\title{
O preto como signo de qualidade e distinção na comunicação da embalagem de alimentos ${ }^{1}$
}

\section{Black as sign of quality and distinction in food packaging communication}

\author{
Carla Pereira
}

Doutora em Arquitetura e Urbanismo pela Universidade de São Paulo (USP), na área de Design. Membro do corpo docente permanente do Programa de Pós-Graduação em Design da Universidade Federal de Campina Grande.

<carlapereira@usp.br>

\section{RESUMO}

Esta pesquisa aborda o conteúdo simbólico veiculado na comunicação da embalagem de alimentos, focando no papel desempenhado pelas cores na construção da mensagem visual. Baseia-se em resultados de pesquisa de doutorado em que foram examinadas embalagens de dez cores distintas. Investigou-se a linguagem das cores como um sistema de signos, apoiando-se na teoria de Saussure e em modelos de classificação e análise propostos por Peirce e pelo Groupe $\mu$. Este artigo faz um recorte do espectro de cores examinadas na tese, descrevendo os resultados obtidos para a cor preta e analisando sua função simbólica na construção da imagem de excelência dos produtos. Conclui-se que as embalagens e rótulos pretos refletem desdobramentos da massificação do gosto pelo luxo no consumo de alimentos industrializados, reproduzindo signos de distinção social.

Palavras-chave: Simbolismo das cores. Comunicação visual. Design de embalagens.

\begin{abstract}
This research discusses the symbolic content broadcasted on food packaging communication, focusing on the role played by colors in constructing visual messages. It is based on doctoral research in which packages of ten distinct colors were examined. The color language was investigated as a sign system. The study was based on Saussurre theory as well as on classifications and analysis models proposed by Peirce and by Groupe $\mu$. This article is a cutout of the color spectrum examined in the thesis, describing the results for black color and analyzing its symbolic role in the construction of product's high quality image. It is concluded that black packaging and labels reflect developments of mass taste for luxury in processed foods consumption, reproducing signs of social distinction.
\end{abstract}

Keywords: Color symbolism. Visual communication. Packaging design.

\section{Introdução}

De recipientes e conservadores em sua origem, a partir da disseminação dos supermercados, em meados do século XX, as embalagens se tornaram dispositivos de estímulo ao consumo e meios de comunicação de massa. Nesse percurso, embora os formatos de mídia tenham evoluído do cartaz para o rádio e a televisão, e, mais recentemente, para a internet, a embalagem, como suporte

1 Pesquisa financiada pela CAPES. 
de comunicação presente no ato da compra, permanece como um importante veículo de promoção de marcas e produtos.

Em função da estandardização de formatos e materiais, determinada pela otimização dos processos produtivos e sistemas de distribuição, a comunicação visual da embalagem tornou-se, em muitos casos, a principal responsável pela particularização estética e diferenciação entre marcas e produtos. Para além dessa função, considerando-se que o design de embalagens é também a representação visual de um conteúdo inserido no discurso publicitário de promoção de marcas e produtos, ele participa de um processo mais amplo de propagação de valores e símbolos.

No contexto da complexidade e diversidade da produção e distribuição de gêneros da época contemporânea, as embalagens precisam comunicar qualidades materiais e imateriais dos alimentos, que se referem não apenas a aspectos biológicos, mas que dizem respeito também à origem ou à tradição dos produtos, bem como à sua confiabilidade, aspectos ligados à satisfação de necessidades psicológicas, emocionais e culturais dos consumidores (Peri, 2006).

De acordo com Claude Fischler (2001), os alimentos são portadores de significados, carregados de imaginário e são adquiridos em parte por estas características. Nos dias de hoje, quando a industrialização afastou os indivíduos do processo de elaboração dos alimentos, e o comércio de autosserviço eliminou a mediação do vendedor, a embalagem vem a ser a principal conexão entre o produto e seu consumidor.

\begin{abstract}
Está-se, portanto, diante de um objeto comunicativo que deve desenvolver uma linguagem capaz de construir discursos cada vez mais complexos e que deve dilatar e modular seus próprios registros linguísticos para permitir ao produto uma condição de autossuficiência comunicativa [...] (Bucchetti, 2002, p. 45, tradução nossa $\left.{ }^{2}\right)$.
\end{abstract}

Embora a linguagem verbal seja considerada o primeiro canal de comunicação, as embalagens também comunicam através de um "canal complementar" composto pelos elementos plásticos do design: as formas,

2 Si è pertanto di fronte a un oggetto comunicativo che deve sviluppare un linguaggio in grado di costruire discorsi via via piu complessi e che deve dilatare e modulare i propri registri linguistici per consentire al prodotto una condizione di autosufficienza comunicativa [...] (Bucchetti, 2002, p. 45). 
as cores, as dimensões (Ferraresi, 2003, p. 17). A despeito das relações de interdependência destes elementos e da importância de cada um para a construção da mensagem visual, a cor possui características que a tornam particularmente adequada a determinados propósitos da comunicação: ela é "[...] um meio de classificar, ordenar e rotular, de opor, associar, e estabelecer hierarquia" (Pastoureau, 1993a, p. 341, tradução nossa³), seu conteúdo semântico a torna um código essencial ao processo de comunicação.

O presente trabalho baseia-se em resultados de pesquisa de doutorado realizada na Universidade de São Paulo, em que foram examinadas embalagens de alimentos nas cores azul, vermelha, amarela, verde, laranja, violeta, rosa, marrom, preta e branca. A pesquisa teve como objetivo identificar, descrever e analisar o sistema de significados da cor no contexto do design de embalagens, observando sua relação com outros sistemas simbólicos da cor na cultura ocidental. Pretendeu-se demonstrar que, a despeito das funções perceptivas, sinestésicas e indicativas comumente desempenhadas pelas cores nas embalagens, na representação de ideias abstratas ligadas aos alimentos, o colorido do design reflete concepções ideológicas e culturais que têm lugar na sociedade contemporânea.

Este artigo apresenta um recorte do espectro de cores examinadas na tese, descrevendo os resultados obtidos para a cor preta e analisando sua função simbólica na construção da imagem de excelência dos produtos tal qual veiculada pelas embalagens.

\section{Os significados simbólicos de uma cor sem cor}

Preto, branco e as diversas tonalidades de cinza são sensações visuais que não apresentam os atributos de matiz e saturação, mas apenas a dimensão de claridade; por essa razão, são denominadas sensações acromáticas. Vistos como representações da luz e da antítese da luz, preto e branco estão na base dos mais antigos sistemas simbólicos das cores. Como a cor da escuridão, das trevas, o preto carrega desde tempos remotos todo o simbolismo negativo da ausência de luz que corresponde à ausência de vida; na mitologia, na literatura, na pintura e em diferentes manifestações da cultura, representa a noite, o medo e o mal (Pastoureau, 2011).

3 [...] a means of classifying, ordering and labelling, of opposing, associating, and establishing hierarchy (Pastoureau, 1993a, p. 341). 
Mas, na medida em que o desapego às cores é visto como signo de austeridade, o preto é valorizado nas práticas sociais. De acordo com Michel Pastoureau (2011, p. 76), o final da Idade Média assinalou um período de intensa valorização do preto "em quase todos os aspectos da vida social".

\begin{abstract}
São, com efeito, os legistas, os juristas, os magistrados membros de certas cortes soberanas os primeiros a mostrar uma nova atração por essa cor [...]. Aos olhos deles, como aos de um grande número de ordens monásticas e religiosas, a cor preta não é infernal ou maléfica mas austera e virtuosa; por essa razão, deve ser escolhida para significar a autoridade pública, a lei e o direito, e mesmo a administração nascente. [...] Pouco a pouco, são imitados por alguns professores universitários e depois por todos aqueles que detêm algum saber. [...] o preto é sinal distintivo de um status particular e de uma certa moral cívica (Pastoureau, 2011, p. 93-94).
\end{abstract}

Outra ambivalência dessa cor diz respeito aos seus sentidos de comedimento e, ao mesmo tempo, riqueza, o que vem a ocorrer quando a produção de tecidos pretos mais caros, de coloração mais intensa e durável, os transformou em artigos de luxo, usados por príncipes e pessoas abastadas no século XVI (Pastoureau, 2011). O alto custo do tecido negro o tornaria uma marca de distinção social, o preto passava a simbolizar elegância e sofisticação, sendo a cor que muitos escolhiam vestir ao serem retratados para mostrar importância e, ao mesmo tempo, seriedade (Harvey, 2003).

Essa ascensão do preto apoia-se numa oposição semântica culturalmente significativa em relação à cor: diz respeito à ausência de cores usada em contraposição ao colorido, contexto em que preto, branco e/ou tons de cinza se colocam como contrários de toda a gama de matizes. Historicamente, o colorido tem sido visto como um polo negativo, opondo-se ao polo positivo representado pela ausência de cor: aparência versus essência, emoção versus razão, disfarce versus verdade, e assim por diante, uma ideia que perpassa a teoria e história da arte (Gage, 1993; Riley, 1995), bem como práticas religiosas e cotidianas (Pastoureau, 2011) e se reproduz na época contemporânea em diferentes esferas da cultura (Batchelor, 2007).

Assim, se no contexto da ética e estética burguesas, o gosto"puro"encontra sua origem na rejeição ao prazer dos sentidos, a tudo o que é considerado "fácil", "vulgar", sem "profundidade" (Bourdieu, 2008), a aversão ao colorido sinaliza austeridade, moralidade, e igualmente erudição e refinamento. 
No âmbito social, é provavelmente a noção de austeridade (considerada em suas diversas possibilidades de interpretação) que faz do preto uma cor recorrente. Austeridade é despojamento, comedimento, ordem e rigor, de onde o preto adquire um sentido de moralidade; e austeridade é igualmente sobriedade, reserva, rigor e formalidade, o que remete também à elegância. Por reunir todas estas conotações, no século XIX, a roupa masculina foi predominantemente escura ou preta (Harvey, 2003).

Historicamente, é principalmente a partir desses dois eixos (austeridademoralidade e austeridade-elegância) que se articula o repertório semântico do preto no design. No sentido de austeridade-moralidade, tem-se o preto dos primeiros telefones, máquinas de costura e de escrever, e dos primeiros automóveis. Na indústria automobilística americana, tornou-se conhecida a frase de Henry Ford referindo-se à disponibilidade de cores do Ford Modelo T, produzido em 1908: "Qualquer cliente pode ter um carro pintado em qualquer cor que ele deseje, desde que seja preto" (Ford,1909 citado por Endt; Grandadam, 1993, p. 32-33, tradução nossa4). Conforme Pastoureau (1993b), os valores do protestantismo, profundamente enraizados na sociedade industrializada do século XIX e início do século XX, foram determinantes para a paleta de cores restrita que caracterizou os primeiros objetos produzidos em grande quantidade:

[...] os valores protestantes tornam-se os valores do capitalismo nascente, depois da sociedade industrial, e por fim aquilo a que, na sociedade ocidental, se chama os «valores burgueses». [...] Se, no século $X I X$, e ainda no começo do século $X X$, a civilização industrial fabricou objectos quotidianos que eram pretos, brancos, cinzentos ou castanhos, como a maioria das roupas masculinas, isso não aconteceu somente por razões técnicas, ligadas à química dos corantes; foi também por razões ideológicas (Pastoureau, 1993b, p. 143-144).

Preto, cores escuras e acromáticas se tornaram as cores características do trabalho e da indústria por remeterem à moralidade e seriedade. De austero e moral, o preto no design torna-se funcional e moderno. Austeridade também corresponde à simplicidade, de onde o formalismo de artistas e designers modernistas das primeiras décadas do século XX, caracterizado pela

4 Any customer can have a car painted any colour that he wants, so long as it is black (Ford,1909 citado por Endt; Grandadam, 1993, p. 32-33). 
geometrização e redução de cores, deu ao preto um papel proeminente na estética moderna.

Nos anos 1920 e 1930, o design de objetos frequentemente recorreu ao preto para representar a ideia de funcionalidade. Na mesma época, a redução da cor que conduziu à simplificação da roupa feminina também fez do preto a cor da mulher moderna, notadamente nos desenhos de Coco Chanel, que transpôs cortes e cores até então tipicamente masculinos para a moda feminina (Luzzatto; Pompas, 1997). O tailleur e vestido pretos, produzidos por diferentes ateliês de costura desde os anos 1930, são considerados ainda hoje peças clássicas do vestuário feminino, símbolos de elegância discreta e sofisticação.

\section{Delimitação do corpus e procedimentos de análise}

Foi realizado um estudo empírico, de abordagem qualitativa, em que foram analisadas as cores de embalagens de alimentos (incluídos alimentos e bebidas não alcoólicas) comercializados em supermercados no Brasil. As ferramentas conceituais de análise utilizadas provêm da semiologia/semiótica. Com base na teoria de Saussure (2012), investigou-se a linguagem das cores como um sistema de signos, cuja estrutura é formada pelas relações de identidade, de associação, de diferenciação e oposição entre seus elementos. O estudo apoiou-se também em modelos de classificação e análise propostos por Peirce (1995) e pelo Groupe $\mu$ (1993). Do modelo de análise elaborado pelo Groupe $\mu$ (1993), utilizou-se a distinção dos signos visuais em signos icônicos (as cores vistas em seus aspectos figurativos) e plásticos (cores como elementos abstratos que dão lugar a interpretações). Da teoria peirceana, recorreu-se à categorização dos signos de acordo com os modos pelos quais representam seus objetos (por semelhança, conexão real ou convenção) para caracterizar as funções desempenhadas pelas cores no design como icônicas, indiciais ou simbólicas.

A seleção do corpus seguiu os princípios de pertinência (único foco), compatibilidade com o sistema a ser analisado, amplitude, homogeneidade e sincronicidade propostos por Barthes (2006). O estudo baseou-se nos nomes de cor que correspondem à divisão do espectro mais comumente utilizada para se referir às cores: branco, preto, vermelho, verde, amarelo, azul, marrom, violeta, rosa, laranja e cinza, os chamados "termos básicos de cor"identificados por Berlin e Kay (1991). Destes, apenas o "cinza" não foi incluído na pesquisa em razão de ser pouco utilizado em embalagens de alimentos, conforme constatado em observações preliminares da pesquisa. 
Partiu-se do pressuposto de que um design que se organiza em torno de uma ou duas cores principais constitui um indício de que estas são elementos importantes da comunicação. Desse modo, foram selecionadas e catalogadas embalagens nas quais as dez cores pré-definidas fossem empregadas como cor predominante (aquela de maior área) ou como segunda cor (segunda maior área) no painel principal, totalizando 612 embalagens de diferentes marcas e categorias de produtos.

Dentro da gama demarcada, foi estabelecido que os designs a serem estudados deveriam apresentar cores facilmente identificáveis e nomeáveis através de observação visual, realizada pela pesquisadora, sendo excluídas da seleção tonalidades intermediárias cuja percepção e identificação das cores não fossem evidentes. Do ponto de vista quantitativo, definiu-se um número mínimo de 50 embalagens para cada cor estudada. Seguindo estes princípios, foram catalogadas 60 embalagens nas quais a cor preta era predominante ou utilizada como segunda cor no design.

Para as análises, foram previamente definidos os princípios norteadores da observação, a fim de minimizar tanto quanto possível a influência de impressões pessoais na interpretação dos significados. Em primeiro lugar, o exame das cores partiu do pressuposto de que a comunicação visual da embalagem tem três finalidades principais: (1) proporcionar visibilidade, (2) informar o que está contido no recipiente, e (3) criar uma expectativa positiva em relação a esse conteúdo. Os signos utilizados são intencionais e seus significados concernem a estes objetivos gerais da comunicação, o que já aponta para determinadas possibilidades de interpretação. Outro princípio que impôs limites ao potencial de leituras foi procurar explicar os sentidos das cores com base no repertório semântico compartilhado no âmbito da cultura, conforme descrito pela literatura (o que exclui impressões e preferências individuais), e nas especificidades do sistema de significação em que estão inseridas (o design de embalagens de alimentos).

Para determinar os aspectos particulares da linguagem visual da embalagem a serem observados, foi tomado como referência o método de análise visual da embalagem elaborado por Marina Cavassilas (2007). Segundo a autora, a comunicação da embalagem veicula representações que dizem respeito a instâncias específicas do packaging - o produto, a marca, o comprador, o utilizador e o próprio recipiente - e seus significados remetem a determinados aspectos dessas instâncias (Cavassilas, 2007).

Por fim, tendo-se em conta que os diferentes elementos do design convergem para os mesmos objetivos de comunicação, as cores das embalagens 
foram observadas e interpretadas em conjunto com os demais elementos significativos - fotografias, desenhos, estilo gráfico e tipográfico, textos, formatos e materiais - que funcionaram como indicadores do sentido que as cores assumem no design.

A análise do material ocorreu em dois níveis. Num primeiro momento, foram identificados os significados relativos às funções específicas que as cores desempenham na comunicação das embalagens de alimentos. Nesta primeira etapa, foram contabilizados os sentidos encontrados para cada uma das dez cores investigadas. Numa fase posterior, foram investigados graus mais subjetivos da significação.

Embora a abordagem da pesquisa seja qualitativa, para um trabalho que investiga a cor como uma forma de linguagem, considerou-se importante contabilizar as ocorrências de sentido das cores no âmbito do sistema investigado, com o propósito de explicitar quando se tratam de casos isolados ou de associações recorrentes, informações de interesse para a discussão e interpretação dos resultados, considerando-se o caráter polissêmico da cor, e, na medida em que as conexões simbólicas dizem respeito não apenas à convencionalidade, mas também à generalidade e à recorrência do significado.

Uma vez que um significante plástico pode representar um ou mais significados em relação a um ou mais aspectos do produto, da marca, do comprador, e assim por diante (Cavassilas, 2007), e que as cores são essencialmente polissêmicas, tornou-se necessário adotar um princípio limitador para a etapa de quantificação. Embora uma única cor possa adquirir vários sentidos no mesmo design (ela pode, por exemplo, simbolizar valores da marca ao mesmo tempo em que funciona como um indicador de variedade do produto), diante da necessidade de se obter dados que permitissem demonstrar objetivamente as recorrências de sentido no âmbito do sistema, optou-se por computar apenas um sentido para cada uma das cores predominantes em cada embalagem, ao qual denominamos significado primário.

No âmbito deste trabalho, o significado primário é o sentido da cor mais claramente explicitado pelo design, aquele que cumpre uma função mais direta na comunicação. Para efeito de contagem, significados subjetivos somente foram registrados quando a cor de fato não cumpria um papel prioritariamente informativo. Este procedimento visou evitar que a polissemia dos significantes cromáticos induzisse falsos resultados, tendendo à supervalorização do aspecto simbólico da cor, já que as cores, mesmo quando utilizadas num sentido literal ou imediato (como na representação da cor do alimento) podem ser interpretadas também em termos conotativos. 
Durante esse processo, a análise do corpus demandou a observação de todo o universo das marcas, categorias, produtos evariedades nele contidas, para identificar os significados de modo objetivo e contextualizado, e compreender o papel da cor no âmbito do sistema em estudo. Desse modo, a identificação dos significados primários das cores no design de embalagens baseou-se:

- Na interação entre cores e significantes não cromáticos das embalagens (textos, fotografias, desenhos, estilo gráfico e tipográfico, textos, formatos e materiais);

- Na estratégia cromática da embalagem em relação a estereótipos visuais de categorias de produtos e categorias de mercado;

- No conceito do produto (imagem pretendida) propagado pela publicidade, pelos fabricantes e agências de divulgação;

- Nos significados das cores difundidos por outros sistemas simbólicos da cor na cultura (repertório compartilhado), conforme descrito pela literatura.

\section{Resultados do grupo preto}

Foram catalogadas no conjunto "preto" as embalagens cuja cor predominante ou segunda cor foi visualmente identificada e nomeada como tal pela pesquisadora, podendo apresentar pequenas variações de tonalidade, considerando a gama relativamente ampla de tons que assumem esta denominação na linguagem verbal (Heller, 2004). Atendendo a estas condições, durante a pesquisa foram registradas 60 embalagens.

Por não ser uma cor característica do universo dos alimentos, o significado do preto na embalagem tende a ser independente de semelhança com a cor do produto embalado, o que evidencia sua função indicial e, principalmente, simbólica. Em mais da metade das embalagens esta cor remeteu a qualidades dos produtos que não são físicas, mas mais propriamente psicológicas e culturais.

Os sentidos primários identificados para o preto foram principalmente convencionais (não motivados). Em 10,0\% das embalagens do conjunto, a cor preta indicou redução ou restrição de nutrientes em produtos identificados como "zero" e "light". Igualmente em 10,0\% dos casos, o preto representou o sabor intenso do alimento, incluindo variedades de produtos identificados como "extraforte". Seu significado mais frequente foi o de qualidade superior, observado em $63,3 \%$ do conjunto, tanto em produtos identificados como "premium", "especial" ou "extra", quanto em marcas associadas a estes conceitos (Figura 1). Outros sentidos foram identificados, porém, individualmente, não obtiveram percentuais significativos. 


\section{Figura 1 - Distribuição dos sentidos primários do preto nas embalagens}

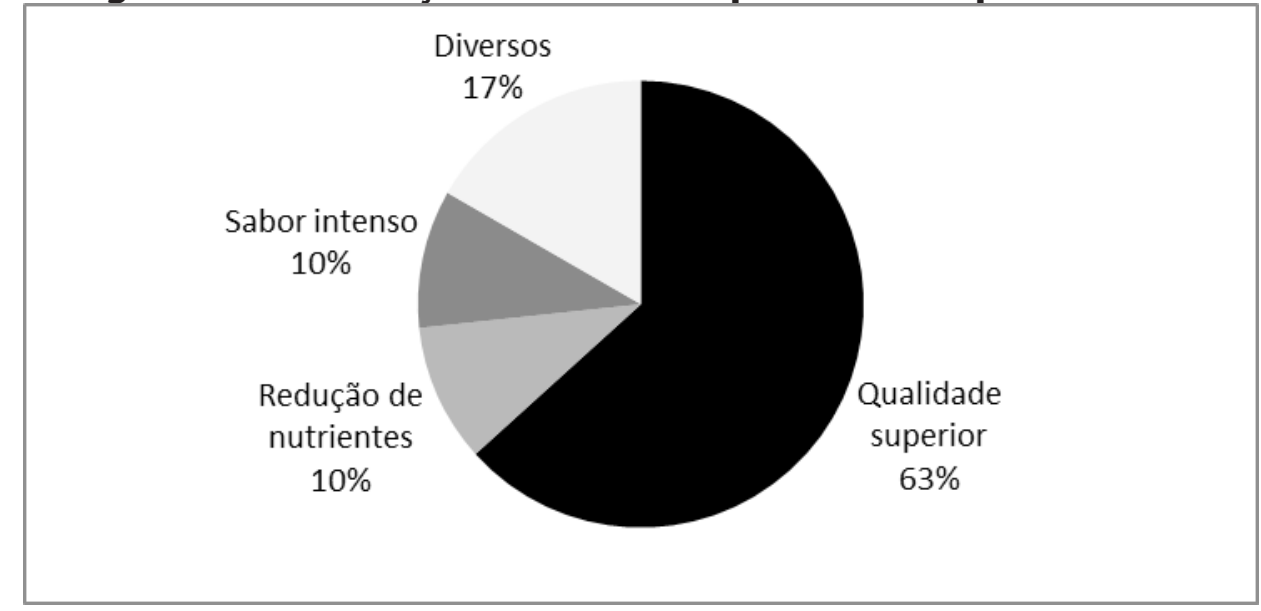

Fonte: a autora

\section{Representações da ideia de qualidade e distinção nas embalagens}

A ideia de alta qualidade vinculada aos produtos alimentícios pode estar relacionada a diversos fatores, que incluem sua procedência, particularidades dos ingredientes, seu grau de pureza, o nível de elaboração da receita, ou outra característica do alimento - material, sensorial ou simbólica - que o distingue dos artigos comuns. São usualmente produtos mais caros e que assinalam alguma superioridade em relação aos demais. Nas embalagens identificadas ao longo da pesquisa, a cor preta foi a que mais frequentemente caracterizou alimentos cujo nível de qualidade é considerado acima do padrão ou cuja imagem é construída nesse sentido.

De modo geral, alimentos industrializados não são considerados artigos de luxo, já que o valor dos produtos e a própria produção em massa descaracterizam a exclusividade desse nível de consumo. Mas a ideia de luxo que sobrevive na sociedade contemporânea não se restringe ao consumo de objetos de altíssimo custo, restritos a uma pequena elite. Mediante o fenômeno do crescimento do mercado da qualidade e dos produtos "especiais" em detrimento do consumo de artigos "populares", o pensamento contemporâneo posiciona o luxo como o gosto pelo supérfluo em todas as esferas sociais, de onde se pode falar em vários graus de luxo, que incluem tanto o luxo de exceção quanto o luxo acessível:

Em nossos dias, o setor constrói-se sistematicamente como um mercado hierarquizado, diferenciado, diversificado, em que o luxo de exceção coexiste com um luxo intermediário e acessível. Esfera daí em diante plural, o luxo "estilhaçou-se", não há mais um luxo, 
mas luxos, em vários graus, para públicos diversos (Lipovetsky; Roux, 2005, p. 15).

No contexto da produção industrial, os produtos que são apresentados como topo de linha - os artigos mais aperfeiçoados, de mais alto nível dentro da produção - simbolicamente se aproximam do artigo de luxo tradicional, no sentido de significar algo excepcional, além do comum. Desse modo, as referências visuais usadas pelo design de embalagens de alimentos comuns para significar alta qualidade, misturam-se àquelas empregadas no packaging de artigos de alto custo, como certos tipos de bebidas, perfumes e joias (Kozac; Wiedemann, 2008).

O uso de materiais de embalagem considerados mais nobres e/ ou acabamentos especiais (como alto-relevo e impressão metalizada ou holográfica) funcionam como marcadores que diferenciam os produtos e os identificam como fora do padrão. Além destas características, o uso de formatos de embalagem exclusivos, o estilo gráfico do design e características cromáticas específicas compõem o discurso visual da qualidade e superioridade, no qual o preto mostrou-se um signo recorrente.

Um exemplo histórico do sentido de excelência do preto no design de embalagens é encontrado no código cromático usado para diferenciar variedades de whisky no início do século passado. Numa época em que esta cor predominava no vestuário masculino simbolizando importância, sofisticação e distinção social (Harvey, 2003), o melhor e mais caro dos três whiskies então produzidos pela família Walker, na Escócia, recebeu um rótulo preto e não de outra cor (Figura 2).

Mais de um século depois, a despeito das mudanças ocorridas nos padrões sociais e culturais e do nível de complexidade alcançado pela produção e consumo de alimentos, a presente pesquisa constatou que os rótulos pretos permanecem um signo de alta qualidade no design embalagens. Isto foi observado não apenas no setor de whiskies, cujo registro histórico permite inferir o contexto que dá origem ao código cromático, mas também nos alimentos e bebidas não alcoólicas que integraram o corpus de análise, demonstrando a resistência do significado da cor ao longo do tempo e sua recorrência em diferentes segmentos do packaging. 
- Figura 2 - Código de cores para whisky de 1906

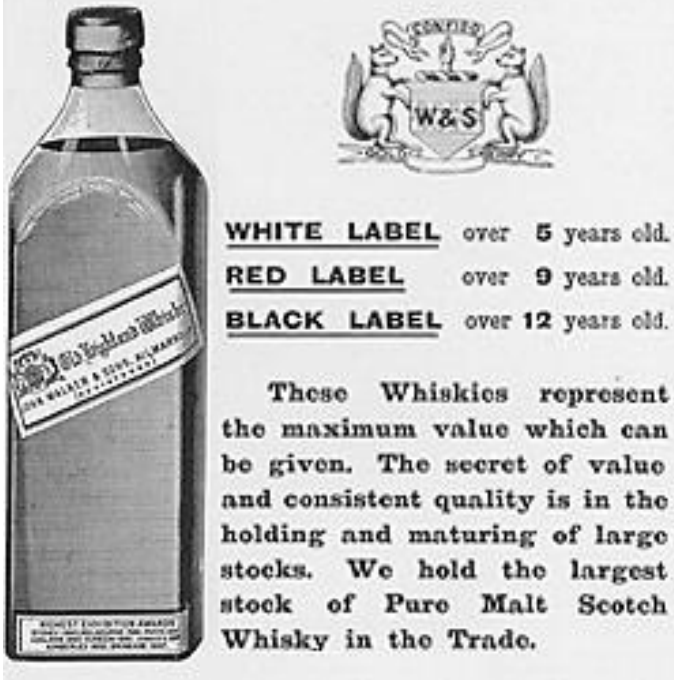

Fonte: John Walker \& Sons

Nas embalagens examinadas, cerca de $60 \%$ dos designs catalogados no grupo preto corresponderam a alimentos da categoria premium, mesmo em se tratando de um estudo restrito ao universo dos supermercados, que não são estabelecimentos especializados em produtos de alto padrão. Nesses designs, signos verbais, visuais e cromáticos combinam-se na representação da alegada superioridade dos produtos, onde o preto está frequentemente associado a acabamentos metalizados que simulam ouro e prata, símbolos tradicionais de luxo e riqueza.

Numa das embalagens analisadas, uma garrafa de vinagre balsâmico (Figura 3), o sentido de nobreza do preto, associado a um fundo claro (quase acromático), é reafirmado pelos elementos dourados que caracterizam o design do rótulo, e por todo um conjunto de referências visuais e verbais contido no design que remete à distinção: o ícone de um castelo apoiado em um listel que contém o nome da marca (uma referência aos brasões heráldicos), além de termos estrangeiros inseridos no rótulo, que remetem à cultura europeia.

Como já exposto anteriormente, os sentidos de sobriedade, reserva, formalidade e elegância atribuídos ao preto foram construídos em virtude da compreensão que se tem dessa cor como uma negação do colorido, a oposição cromático/acromático correspondendo no plano semântico à vulgaridade/ distinção, exibição/reserva, informalidade/formalidade, deselegância/ elegância, e assim por diante. 


\section{Figura 3: Embalagem de vinagre balsâmico}

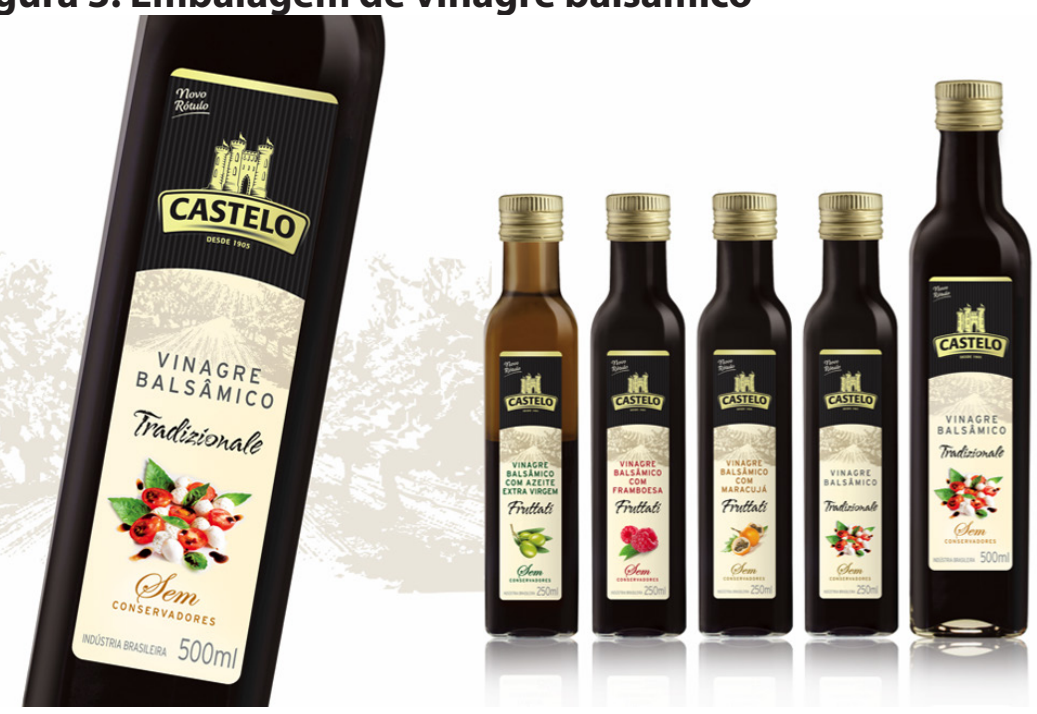

Fonte: Bench Mark Design

Historicamente, seu sentido de distinção é extraído da oposição que representa em relação ao colorido, sobretudo quando o colorido é o senso comum. Quando, por exemplo, no início da produção de automóveis, as limitações técnicas tornavam o acabamento colorido mais caro, um automóvel preto denotava simplicidade e comedimento, mas na medida em que novas tecnologias de coloração banalizaram os carros coloridos, o preto tornou-se a cor característica dos modelos sofisticados (Pastoureau, 1993a). Em outras palavras, seja para a simplicidade ou para o luxo, o preto sinaliza a diferença.

De modo semelhante, o packaging de alimentos é essencialmente um universo multicolorido, no qual a ausência de matiz é fortemente significativa. A embalagem acromática chama a atenção para o produto, o diferencia do uso comum, o particulariza, a cor torna-se a princípio um signo indicial. Mas, para além desse papel indicativo, o preto nas embalagens também assume uma função simbólica.

A teoria peirceana define o símbolo como um signo que se refere ao objeto por convenção e, além da convencionalidade, a generalidade e a recorrência também Ihe são características. O símbolo não se refere a uma coisa particular, mas a conceitos gerais, e só existe em virtude de uma lei ou hábito (Peirce, 1995). Conforme exposto por Caivano (1998), cores funcionam como símbolos quando os mesmos significados lhes são frequentemente atribuídos, independente do contexto em que são usadas. Seguindo esta linha de pensamento, a cor preta como signo de distinção (nível superior) pode ser 
considerada uma conexão simbólica, já que este significado não está restrito ao universo das embalagens, ele tem um caráter geral e recorrente em diferentes instâncias da cultura (Pastoureau, 1993b; 2011; Harvey, 2003).

Nos designs do corpus, embora a comunicação do nível superior dos produtos se organize por meio de signos visuais, os termos "premium", "especial", "extra","reserva"e"gourmet"são também usados como marcadores de qualidade. Embora todos remetam ao sentido de padrão elevado, "especial" e "reserva" remetem mais diretamente à exclusividade, e "gourmet" à gastronomia.

A sociedade presente tem redescoberto a prática culinária como profissão e como atividade de interação social, assim como tem valorizado a cultura gastronômica. Numa época em que se assiste ao aumento do interesse por produtos de alta qualidade nos diferentes setores da produção de bens (Lipovetsky; Roux, 2005), a valorização da gastronomia fez surgir na produção industrial dealimentos a categoria gourmet. Nesse segmento, a qualidadealegada do produto diz respeito mais diretamente a suas características sensoriais. Os produtos desta categoria apresentam sabores e aromas diferenciados, sabores considerados mais sofisticados em comparação ao produto comum, podem conter ingredientes nobres ou ser produzidos de um modo peculiar que favoreça suas características de sabor. São simbolicamente associados à ideia de haute cuisine, da cozinha como uma forma de arte.

\section{- Figura 4: Embalagem de azeite de oliva}

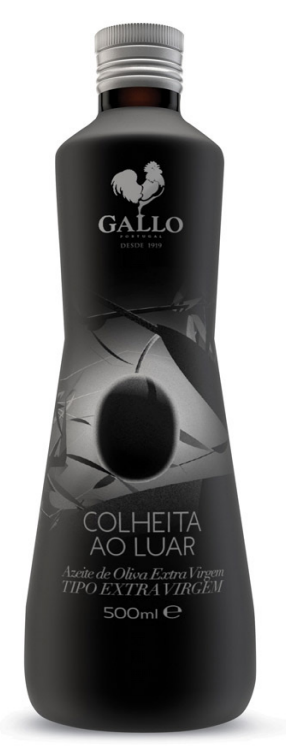

Fonte: Gallo 
Num dos designs observados, uma embalagem de azeite de oliva (Figura 4), as cores do frasco preto com impressão e tampa prateadas representam a noite e o brilho do luar (sentidos primários relacionados ao nome do produto). No nível simbólico, este padrão cromático - combinado ao tratamento fosco aplicado ao vidro, ao estilo tradicional da tipografia e à sobriedade da composição minimalista - sinaliza o caráter invulgar e gourmet do alimento, reafirmado pela mensagem verbal "extra virgem". Conforme assinala Bucchetti:

A imagem do luxo parece, por um lado, permanecer ancorada no passado, nas expressões de opulência, com suas reminiscências relacionadas com a atmosfera "de corte", mas, ao mesmo tempo, parece ter encontrado uma dimensão que se expressa através da apropriação das formas visíveis do silêncio e então por meio de estruturas essenciais, rarefeitas, evanescentes, que se contrapõem a um universo denso de traços semânticos (Bucchetti, 2005, p. 90).

No contexto das embalagens examinadas, tanto nas abordagens de design com maior adensamento visual, quanto nas que tendem ao minimalismo, o preto se apresenta como cor característica.

\section{Figura 5 - Embalagem de salgadinho de batata}

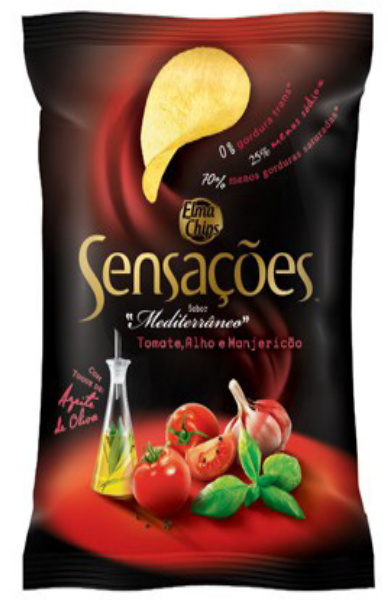

Fonte: PepsiCo Inc. | Brasil

Noutro exemplo do corpus, um salgadinho de batata - artigo muito distante do universo de pratos exclusivos elaborados com ingredientes raros ou assinados por chefs de cozinha renomados - apresenta-se como um produto 
gourmet por oferecer sabores vistos como mais sofisticados do que aqueles da linha comum. O produto é de baixíssimo custo, a embalagem estrutural é de tipo padrão, saco de filme plástico metalizado, mas o discurso visual do design é o da sofisticação (Figura 5).

No contexto do alimento industrializado de consumo de massa, o produto é um exemplo extremo do "luxo" acessível, um luxo simbólico, meramente visual. A embalagem não contém apenas certo alimento, mas todo o imaginário evocado por seus signos verbais e visuais: o nome do sabor "Mediterrâneo", requintado se comparado ao simples "queijo" do salgadinho comum; a imagem do frasco de azeite, que sugere ingredientes nobres, reforçada pela mensagem verbal "Com Toque de Azeite de Oliva"; o acabamento fosco do material, que o distingue do brilho característico do plástico comum; o logotipo dourado com letras serifadas; e, por fim, o predomínio do preto, que se opõe ao colorido intenso das embalagens dos salgadinhos comuns e é a cor arquetípica da sofisticação e do nível superior (Pastoureau, 1993b, 2011).

Conforme Bucchetti (2002, p. 28, tradução nossa5), na medida em que os bens de consumo passaram a atuar cada vez mais na realidade social não só como mensagens comunicativas, mas também como uma linguagem que permite às pessoas encontrarem sua própria identidade, "a embalagem tornase um dos dispositivos para a definição ou para a tradução dessa linguagem". Ela deve possibilitar ao consumidor elaborar representações que dizem respeito à marca e ao produto, mas também deve lhe permitir elaborar imagens de si mesmo.

\section{- Figura 6 - Embalagem de água mineral}

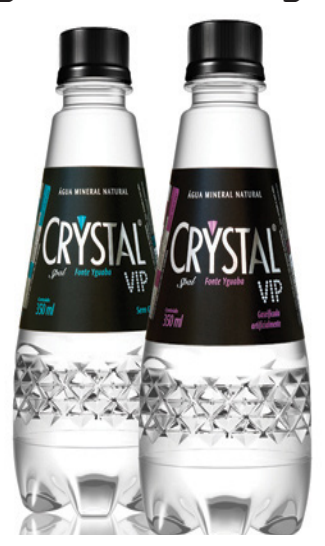

Fonte: Muller Camacho Design

5 [...] il packaging diviene uno dei dispositivi per la definizione o per la traduzione di questo linguaggio [...]. (Bucchetti, 2002, p. 28) 
O exemplo mais característico desse princípio nos designs examinados foi o de uma embalagem de água mineral. A água engarrafada é igual a muitas outras, não consta no rótulo nenhuma informação que a diferencie das demais (na composição ou no sabor), mas a cor do rótulo é radicalmente diferente. No mercado brasileiro, onde embalagens de água tradicionalmente recorrem a azul e branco para enfatizar sua "pureza" e característica refrescante, a garrafa de rótulo e tampa pretos se destaca por contrariar a linguagem cromática estabelecida. O preto sinaliza não se tratar de um produto comum e a informação cromática é reiterada pela inscrição "VIP" contida no rótulo - abreviatura da expressão inglesa very important person, que se refere a pessoas de prestígio ou poder (Figura 6).

O significado da cor é confirmado pelos demais elementos plásticos do design, como o formato exclusivo, o tamanho e textura da garrafa (que simula o formato de cristais), além de outro signo cromático que remete à importância: o acabamento prateado da tipografia. Para além de uma imagem do produto, a embalagem remete diretamente a uma imagem do próprio consumidor, ao se identificar com as conotações de distinção social que caracterizam a denominação "VIP".

\section{Considerações finais}

É reconhecido que os alimentos são carregados de significação, exercem funções simbólicas e sociais, e, ao consumi-los, os indivíduos atribuem a si mesmos as características que o alimento veicula: os alimentos parecem transferir aos consumidores também suas características imateriais e essa incorporação também está vinculada ao sentimento de identidade coletiva, o consumo de um alimento incorpora o indivíduo a um sistema culinário, e deste modo, ao grupo que o pratica (Fischler, 2001).

Hoje, grande parte dos alimentos consumidos são produtos industriais: projetados, transformados, produzidos e embalados. São reconhecidos por suas embalagens, objetos que mediam a relação dos indivíduos com esses produtos. Enquanto na culinária o simbolismo do alimento está implícito em seu contexto de uso, nas regras de preparo, nos rituais de consumo, no alimento industrializado ele é explicitado pela embalagem. É através das embalagens que os alimentos se autoproclamam "refinados", "modernos", "saudáveis", "naturais", "tradicionais" e assim por diante, refletindo a heterogeneidade dos grupos de consumo.

Nesse contexto, o design da embalagem vem a ser a materialização de uma imagem criada para satisfazer necessidades culturais e sociais. Para além 
de suas funções objetivas e informativas, ele é também a tradução visual de um conceito que representa o alimento e, ao mesmo tempo, aquele que o consome. Nesse sistema simbólico, as cores ultrapassam as exigências perceptivas e indicativas do design para sinalizar valores éticos e estéticos, comportamentos, estilos e padrões difundidos na cultura contemporânea.

Esta pesquisa mostrou que o design dialoga com outros sistemas de significação e recorre ao tradicional simbolismo das cores para construir essas imagens. Foi constatado que o design de embalagens contemporâneo resgata e difunde um sentido do preto que remonta ao século XVI e que teve seu ápice como convenção social no traje preto masculino do final do século XIX: a cor preta como representação de luxo, elegância e importância, uma cor para as elites, um signo de distinção.

O uso do preto na embalagem como signo de qualidade superior reflete práticas de diferenciação social e de identidade coletiva relacionadas ao consumo de alimentos. $O$ rótulo preto representou o artigo de alto padrão, cujo consumo simbolicamente incorpora o indivíduo a uma elite de consumidores que apreciam a excelência, a sofisticação possível em se tratando de produtos alimentícios de consumo de massa. O preto dos alimentos premium e gourmet reflete ainda desdobramentos da massificação do gosto pelo luxo na produção e consumo dos alimentos industrializados, contexto em que o discurso da gastronomia, da "qualidade superior" e da "sofisticação" reproduzem signos de distinção social.

\section{Referências bibliográficas}

BARTHES, Roland. Elementos de semiologia. São Paulo: Cultrix, 2006.

BATCHELOR, David. Cromofobia. São Paulo: Senac, 2007.

BENCH MARK DESIGN. Embalagem de vinagre balsâmico. Disponível em: <http:// www.bench.com.br/balsamico.html>. Acesso em: 03 mar. 2014.

BERLIN, Brent; KAY, Paul. Basic color terms: their universality and evolution. Los Angeles: University of California Press, 1991.

BOURDIEU, Pierre. A distinção: crítica social do julgamento. São Paulo: Edusp, 2008.

BUCCHETTI, Valeria. La messa in scena del prodotto. 2. ed., Milano: Franco Angeli, 2002.

Packaging design: storia, linguaggi, progetto. Milano: Franco Angeli, 2005.

CAIVANO, José Luis. Color and semiotics: a two-way street. Color Research and 
Application, v. XXIII, 6 dec. 1998.

CAVASSILAS, Marina. Clés et codes du packaging. Paris: Lavoisier, 2007.

ENDT, Evert ; GRANDADAM, Sabine. Design for everyday objects. In: Jocelyn de Noblet (Ed.). Industrial Design: reflection of a century. Paris: Flammarion, p. 30-36, 1993.

FISCHLER, Claude. L'homnivore: le goût, la cuisine et le corps. Paris: Odile Jacob, 2001.

FERRARESI, Mauro. II packaging. Milano: Franco Angeli, 2003.

GAGE, John. 1993. Colour and culture: practice and meaning from antiquity to abstraction. London: Thames and Hudson, 1993.

GALLO. Embalagem de azeite de oliva. Disponível em: <http://www.gallooliveoil. com/br/produtos.aspx>. Acesso em: 13 set. 2011.

GROUPE $\mu$. Tratado del signo visual: para una retórica de la imagem. Madrid: Catedra, 1993.

HARVEY, John. Homens de preto. São Paulo: Unesp, 2003.

HELLER, Eva. Psicología del color: cómo actúan los colores sobre los sentimientos y la razón. Barcelona: Gustavo Gili, 2004.

JOHNWALKER \& SONS. Código de cores para whisky de 1906. Disponível em: $<\underline{\text { http:// }}$ www.keepwalking.pt>. Acesso em: 24 mar. 2011.

KOZAC, Gisela; WIEDEMANN, Julius. Package design now! Köln: Tashen, 2008.

LIPOVETSKY, Gilles e ROUX, Elyette. O luxo eterno: da idade do sagrado ao tempo das marcas. São Paulo: Companhia das Letras, 2005.

LUZZATTO, Lia; POMPAS, Renata. I colori del vestire. Milano: Hoepli, 1997.

MULLER CAMACHO DESIGN. Embalagem de água mineral. Disponível em: < $\underline{\text { http:// }}$ www.mullercamacho.com.br>. Acesso em: 20 abr. 2011.

PASTOUREAU, Michel. Colour, design and mass consumption: the history of a difficult encounter (1880-1960). In: Jocelyn de Noblet (Ed.). Industrial Design: reflection of a century. Paris: Flammarion, p. 336-341, 1993a.

Dicionário das cores do nosso tempo: simbólica e sociedade. Lisboa: Editorial Estampa, 1993b.

Preto: história de uma cor. São Paulo: Editora Senac, 2011.

PEIRCE, Charles S. Semiótica. São Paulo: Perspectiva, 1995. 
PEPSICO Inc. Embalagem de salgadinho de batata. Disponível em: < http://www. pepsico.com.br/elma-chips-sensacoes>. Acesso em: 17 fev. 2014.

PERI, Claudio. The universe of food quality. Food Quality and Preference, v. 17, p. 3-8. 2006. Disponível em: <http://www.sciencedirect.com>. Acesso em: 25 mai. 2009.

RILEY, Charles A. Color codes: modern theories of color in philosophy, painting and architecture, literature, music and psychology. London: University Press of New England, 1995.

SAUSSURE, Ferdinand. Curso de linguística geral. São Paulo: Cultrix, 2012.

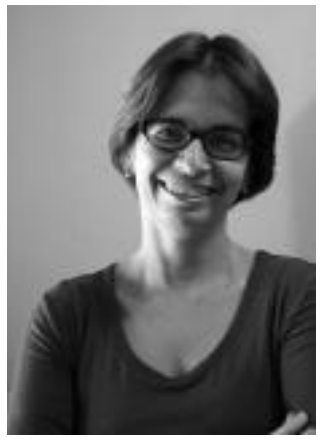

Recebido em: 17/4/2016

Aceito em: 9/6/2016

Endereço da autora:

Carla Pereira <carlapereira@usp.br>

Programa de Pós-Graduação em Design da Universidade Federal de Campina Grande Unidade Acadêmica de Design

Rua Aprígio Veloso, 882 - Bloco BO

58429-900 - Campina Grande - Paraíba - PB - Brasil 